\title{
LA DISPUTA DE L'ASE Y OTROS EQUINOS PARLANTES EN LA LITERATURA CATALANA MEDIEVAL
}

\author{
Llúcia Martín Pascual \\ Universidad de Alicante
}

\begin{abstract}
RESUMEN
El presente trabajo se centra en la figura del animal parlante - el asno y el caballo- que discute con el hombre acerca de la dignidad humana o simplemente presenta una situación paródica relacionada con la crítica a los estamentos religiosos. Nos referimos especialmente a dos textos del siglo XIV, la Disputa de l'Ase de Anselm Turmeda y la narración burlesca anónima escrita en verso Disputació d'en Buch ab son cavall. Además constatamos algunas fábulas de Francesc Eiximenis con protagonistas animales que reflexionan sobre lo que piensan de los humanos.
\end{abstract}

PALABRAS CLAVE: fábulas, disputa, asno, caballo, bestiarios, Anselm Turmeda

\begin{abstract}
The aim of this paper is to study the singular characteristic of the animal wich speak with humans generally the ass and the horse. The works are about the human dignity in a parodic situation, in other to critisize religious stablishment. We are talking aobut two pieces of 14th century: Disputa de l'Ase of Anselm Turmeda and am anonymous burlesque story called Disputació d'En Buch ab son cavall. Also, there are some fables of Francesc Eiximenis with talking animals, and they argue very angrily about human dignitiy.
\end{abstract}

KEY WORDS: fables, discussion, ass, horse, bestiaries, Anselm Turmeda

La literatura catalana medieval no fue ajena al gusto por las fábulas con protagonistas animales, tanto las conocidas como fábulas esópicas ${ }^{1}$ comolas procedentes de la tradición oriental. Entre estas últimas, además del Llibre de les bèsties de Ramon Recibido 9-X-2015. Aceptado: 23-XI-2015

\footnotetext{
1 La recepción de las fábulas esópicas en catalán parece tardía a tenor de los datos de los que disponemos puesto que solo se conservan ediciones de 1550 y 1576, aunque esto no equivale a un desconcimiento de los materiales ni a una posible relación de textos perdidos anteriores. El bibliófilo Ramon Miquel y Planas editó estos impresos con el título, Llibre del sabi y clarissim fabulador Isop: historiat y notat als marges del llibre y ara novament corretgit per R. Miquel y Planas en vista de les edicions de 1550 y 1576 y de les posteriorment publicades en català, Barcelona, en casa de Fidel Giró, 1908. No contamos con un estudio exhaustivo sobre la colección de fábulas esópicas catalanas, solo algunas aproximaciones como L. Martín, «Contribució a l'estudi de la versió catalana de les faules d'Isop i la seua difusió en la literatura medieval», en J.M. Lucía (ed.), Actas del VI Congreso de la Asociación Hispánica de Literatura Medieval (Alcalá de Henares, septiembre 1995), vol. 2, Universidad de Alcalá de Henares, pp. 1123-1137. En prensa, el artículo de María Jesús Lacarra, «Los enigmas de las Faules d'Isop», Caplletra. Revista Internacional de Filología.
} 
Llull, la más conocida muestra de la recepción del Calila e Dimna ${ }^{2}$ en tierras catalanas, encontramos otros textos que evocan fábulas procedentes del Barlaam e Josafat, como por ejemplo la Faula del Rossinyol de Cerverí de Girona. ${ }^{3}$

Autores doctrinales como Francesc Eximinenis y predicadores como Vicent Ferrer hicieron uso de la fábula como recurso didáctico así como también del enorme potencial ejemplarizante de los bestiarios, paradigmas animales que transmiten unas normas de comportamiento equiparable al humano. En este sentido, se conservan varias versiones de bestiarios catalanes, completos y fragmentarios, procedentes de un anónimo toscano. ${ }^{4} \mathrm{El}$ ejemplo animal no fue exclusivo de la literatura doctrinal, pues también la poesia lírica y los textos narrativos se enriquecieron con semblanzas animales, más aún cuando poesía y narración adquieren un componente moralizante o satírico. Es el caso de los ejemplos animales de la poesía de Ausiàs March, quien explota notablemente el recurso, y de la discusión antifemenina del Spill de Jaume Roig, ${ }^{5}$ por citar algunos de los ejemplos más significativos.

La relación entre los animales y el hombre es uno de los temas preferidos de las fábulas. Partiendo de la idea de superioridad humana, en muchos casos se cuestiona este principio que deja en ridículo a los reyes de la Creación. Como ejemplo de esta situación, es significativo el pasaje relatado en el Llibre de les bèsties de Ramon Llull ${ }^{6}$ sobre la embajada que los animales envían al reino de los hombres y que acaba con humillaciones a los primeros, una situación que no solo provoca tensión entre hombres y animales sino que se ve agravada por las astucias y arterías de Na Renart.?

2 Aunque el Llibre de les Bèsties es la obra más conocida que reproduce apólogos del Calila e Dimna, existe un texto sapiencial bastante desconocido, titulado la Doctrina d'En Pacs que incluye pequeñas alusiones a cuentos del Calila, L. Martín, «Algunes notes sobre la recepció del Calila e Dimna al català i la Doctrina d'en Pacs», Randa. Homenatge Jordi Carbonell, 60 (2007), pp. 25-39.

3 M. Cabré, Cerverí de Girona and his poetic traditions, London, Tamesis, 1999, pp.152-179.

4 Se conservan dos versiones completas y tres fragmentarias, además de algunas hojas sueltas que remiten a un bestiario en catalán de finales del XIV o inicios del XV, traducción de alguna versión toscana anterior: L. Martín, «Nuevas aportaciones sobre la transmisión del Bestiario catalán», Revista de Literatura Medieval, 24 (2012), pp. 155-172.

5 L. Martín, La tradició animalística en la literatura catalana medieval, Alacant, Institut de Cultura Juan Gil-Albert, Universitat d'Alacant, Conselleria de Cultura, Educació i Ciència, 1996.

${ }^{6}$ La edición del Llibre de les bèsties que utilizamos es la que realizó Antoni Bonner como libro séptimo del Llibre de Meravelles: Obres Selectes (1989), ed. de Antoni Bonner, Palma de Mallorca, Moll (1a edición en inglés, Selected Works, Princeton 1985).

7 Este episodio se desarrolla en el capítulo quinto del Llibre de les bèsties. El león envía unos mensajeros con regalos al rey de los hombres para entablar buenas relaciones pero se encuentra con un monarca déspota, sin atisbos de generosidad, corrupto y maleducado que somete a su pueblo a múltiples vejaciones. Los animales, descontentos, vuelven a su territorio pero se encuentran con que su propio rey, el león, ha quebrantado la confianza de uno de sus consejeros a instancias de Na Renart, el leopardo, y ha violado a su mujer, por lo que se entabla una lucha entre el leopardo y los defensores del león que acaba con la muerte del primero y la impunidad del pecado cometido, una treta más de la traidora Na Renart. 
El franciscano Eiximenis también recurre a este cuestionamiento sobre la bondad humana y en algunas de sus fábulas encontramos animales que se sienten amenazados por los hombres y reflexionan sobre su poder.

Sin embargo, hay un tipo de relación animal-hombre que se desarrolla por medio de la disputa, el diálogo, un desdoblamiento que permite al autor poner en boca del animal razonamientos o críticas que de otra manera serían impensables, pero al propio tiempo reflejan un carácter paródico ya que resulta excesivamente pedante que un animal ridiculice a su oponente. Para este tipo de discusiones se escoge a dos animales: el caballo y el asno. Dos figuras cercanas pero en algunos casos opuestas que nos han dejado algunas de las páginas más divertidas pero también ejemplarizantes de la literatura catalana medieval. Nos centraremos en dos textos del siglo XIV, principalmente la Disputa de l'Ase de Turmeda y una narración burlesca escrita en verso, la anónima Disputació d'en Buch ab son cavall.

\section{El caballo}

Las dos versiones completas del Bestiario catalán nos muestran una característica del caballo que no se relaciona con los papeles que más tarde desarrollará en narraciones caballerescas fundamentalmente. El Bestiario remite a una atribución recogida en las Etimologiae isidorianas respecto al significado del nombre del animal y relacionada con su capacidad para cavar y encontrar agua: ${ }^{8}$

Lo cavall sí ha en si aytal natura: que si hom lo tenia sinch jorns menys de beure, e puys lo lexave hom en loch hon no hagués ayga, com hi veés, e és stat provat moltes vegades, que si neguna vena d'ayga passava dejús la terra, que mantinent la sent, e fér-hi de sobra de quatre peus, e crida molt fort; e axi coneix hom que aqui ha deu d'ayga. E en aquesta manera són estat presos castells qui era assetgats, per tal com los tolia hom l'ayga qui entrava dins lo castell per conduyt.

En cambio, una enciclopedia como el Livres dou Trésor contiene un extenso capítulo sobre las propiedades del caballo, su comportamiento noble en la batalla, las hazañas de caballos memorables como los de Julio Cesar y Alejandro, las diferentes clases de cabalgaduras, pero nos llama la atención la descripción física del animal: ${ }^{9}$

E deu hom guardar quatre coses al cavall, segons opinió dels antichs: forma, bellesa, bonesa e color. Cor en la forma del cavlla deu hom consirar que se carn e sos ossos sien forts e durs e fundats; que sien ben alts, segons sa força; sos costats deuen ésser lonchs e plens, e les anques grans e redones, e amples cuxes, e grans

\footnotetext{
8 Bestiaris, a cura de Saverio Panunzio, Barcelona, Barcino, 1963, p. 123. El caballo se compara a aquellos hombres que no conocen la gracia y la misericordia divina pero que reconocen sus pecados y hacen penitencia. La traducción de este fragmento y las posteriores referidas a obras en catalán son mías. Versión original.

9 B. Latini, Llibre del Tresor, versió catalana de Guillem de Copons, vol II, a cura de C.J. Wittlin, Barcelona, Barcino, 1976, p. 94. Versión original.
} 
pits, e sia molt ubert, e son cors sia tacat de negre e grossitud, los peus sechs e ben cavats dedins.

En la bellesa deus guardar que haje petit cap e sech, que 1 cuyr se tinga ab los ossos, orelles curtes dreçades en alt, grans ulls, neguex lo cap dret quax semblant a cap de moltó, clims spessos, e coha ben velluda, ungles soldades, fermes e redones.

En bondat guarda que haje cor ardit, alegra andadura, e membres tremolants, ben corrent e ben aturant a ta voluntat. E sàpies que la spertesa del cavall és coneguda a les orelles, e sa força als membres ballans e tremolans.

Encara ta cové pensar en la color baig o gris pomellat, o negre o blanch moscat, o d'altre color que poràs triar mellor e pus avinent.

Se nos hace imposible no reconocer la belleza del animal en las novelas de caballería, ni tampoco observar la imagen del caballero a lomos de su montura. Ahora bien, pocas veces encontramos descripciones en estas novelas. Una de las más significativas es la primera aparición del caballero -aún escudero- Tirant lo Blanc, que se dirige a las fiestas organizadas con ocasión de la boda del rey de Inglaterra. El joven, montado en su caballo y dormido, encuentra a Guillem de Varoic en una ermita, quien después de una vida entregada a la caballería se ha retirado a la contemplación y se convertirá en el maestro del futuro caballero. Esta escena la reproduce Joanot Martorell en el prólogo del Llibre de l'orde de cavalleria de Ramon Llull, un tratado breve que el mallorquín escribió pensando en la regeración del estamento caballeresco. De los siete capítulos que conforman el tradado, el número cinco, dedicado a las armas, contiene una descripción de la función de la montura: ${ }^{10}$

Cavayl és donat a cavayler per significança de nobilitat de coratge, e per so que sie pus alt encavalcat que altre home, e que sie vist de luny, e que més coses tengua dejús si, e que enans sie a toto so que s cové a la honor de cavaylaria que altre home.

En otro tipo de textos caballerescos, como el relato en verso de Guillem de Torroella, la Faula, el mundo mágico que caracteriza esta narración se ve también reflejado en la descripción de un caballo bellamente engalanado que conducirá al protagonista ante el rey Arturo. La Faula es una de tantas narraciones relacionadas con la materia artúrica en la que encontramos un protagonista que pasa del mundo real al fantástico para recibir un encargo del mítico Arturo, quien a través de una visión producida por la espada Escalibur, se lamenta de la decadencia de los valores caballerescos. No obstante esta lección moral, la obra despliega en su breve contenido

\footnotetext{
10 R. Llull, Llibre de l'Orde de Cavalleria, a cura d'Albert Soler, Barcelona, Barcino, 1988, p. 204. La traducción aquí si se considera oportuno. A continuación se describen los paramentos que deben llevar los caballos para protegerse tanto a ellos mismos como a su señor. Encontramos una descripción similar en clave alegórica en la narración en verso de Pere March, Arnés del Cavaller, en P. March, Obra completa, a cura de Lluís Cabré, Barcelona, Barcino, 1993, especialmente pp. 223-229.
} 
una descripción extraordinaria del lugar que el protagonista atraviesa hasta llegar a la cueva donde viven Arturo y Morgana. ${ }^{11}$

Con este tratamiento positivo encontramos ejemplos de caballos que mantienen una especial divergencia con otros animales a favor de los hombres, como por ejemplo el caballo que huye del león en el Calila e Dimna y se refugia en el mundo de los hombres, hecho que reproduce el Llibre de les bèsties de Ramon Llull, ${ }^{12}$ quien además reconoce la nobleza de este animal que prefiere vivir con el género humano antes que en un reino gobernado por un león sometido a su falsa consejera, como es la zorra Na Renart.

Pero nos interesa el aspecto irrisorio del caballo de la Disputació d'en Buc y su carga irónica dirigida a la ridiculización del sacramento de la confesión. La crítica a los sectores clericales, una de las manifestaciones populares de la crisis generada por el Cisma de Occidente, es uno de los componentes del fabliaux, género que surge en la literatura francesa y que se caracteriza por el abandono de la forma de literatura cortés y un acercamiento a la realidad ciudadana que se va consolidando a lo largo del siglo XIV. La literatura catalana no fue ajena a esta forma literaria y, entre la escasa producción ficcional del siglo XIV, encontramos varias obras que se pueden calificar de fabliau $x^{13}$ pero que la terminología literaria catalana prefiere denominar «contes plaents» precisamente para diferenciarla del género francés.

Con este nombre de «contes plaents» encontramos obras como:

- El libre de Fra Bernat, obra en verso que describe la desmesurada lujuria de los frailes.

- El Testament d'en Bernat Serradell, obra también en verso que critica la codicia de los religiosos en el momento de la muerte de un cristiano.

- El sagristà i la burgesa, un triángulo amoroso en el que un sacristán sale malparado por su lujuria.

11 G. de Torroella, La Faula, a cura de Anna Maria Compagna, Barcelona, Publicacions de l'Abadia de Montserrat, 2007. Es imprescindible el artículo de L. Badia, «De la Faula al Tirant passant pel Llibre de Fortuna e Prudència», en Traducció i modernitat als segles XIV i XV. Estudis de cultura literaria i lectures d'Ausiàs March, Barcelona, Valencia, Institut Interuniversitari de Filologia Valenciana/ Publicacions de l'Abadia de Montserrat, 1993, pp. 93-128.

12 El caballo y el buey, descontentos con la elección del León como rey, huyen al reino de los hombres donde son acogidos de forma desigual: mientras que el caballo es honrado por su señor, el buey se convierte en animal de trabajo y su carne en alimento. Por este motivo el buey vuelve al reino animal, entabla amistad con el león lo que provoca la envidia de Dimna -en el libro árabe- y de Na Renart en el libro luliano. A causa de esta envidia ambos animales urden una trama que acabará con la vida del buey.

13 A. Annichiaricco, «Narracions en vers» catalane medievali. Apunti e Materiali per una Guida bibliográfica, Roma, Edizioni di Storia e Letteratura, 2003; A. Ottaiano, «Els fabliaux catalans: anàlisi d'una definició», Miscel lània Joan Fuster. Estudis de Llengua i Literatura, VII; Barcelona-València, PAM, 1993, pp. 5-43. 
- Los siete cuentos en prosa ${ }^{14}$ incluídos en la Disputa de l'Ase de Anselm Turmeda narrados por el asno protagonista que refieren cada uno de los siete pecados capitales que comenten los religiosos.

- La Disputació d'En Buch ab son cavall, una ridiculización del sacramento de la confesión.

La Disputació d'en Buch ab son cavall es una composición de 343 octosílabos pareados escrita en la segunda mitad del siglo XIV. Solo se conserva una copia del texto en el ms. 377 de la Biblioteca Municipal de Carpentràs, el códice que reúne la narrativa catalana (u occitano-catalana) en verso más destacada del siglo xIV. ${ }^{15}$ El texto de la Disputació se conoce desde finales del XIX, si bien hasta 1911 no se realizó una edición más rigurosa por Louis Faraudo de Saint-Germain y, aunque no ha gozado de las preferencias de la crítica, a finales del siglo xx se publicó una edición divulgativa, junto con otros textos narrativos en verso, a la que nos referiremos en las citas de esta obra. ${ }^{16}$

La finalidad del anónimo autor es parodiar elementos de la liturgia cristiana, sobre todo la confesión y la penitencia sin apenas intención moralizadora, aunque no es una opinión unánime de la crítica. ${ }^{17}$

El poema narrativo es un debate entre el caballero En Buch, en realidad un astuto ladrón, y su caballo, que actúa de voz de la conciencia recordándole su comportamiento vil y malvado. La obra tiene apariencia de contrafactum de sermón, empieza con una recriminación del caballero a su caballo acusándole de robar la comida de los otros animales, a lo que el segundo responde que es el propio. En Buch quien debería reflexionar ya que él es también un ladrón. En Buch se defiende alegando que el ladrón era su padre y él ha heredado la fama por tener el mismo nombre que su progenitor. El diálogo se convierte en una sarta de insultos mutuos que desemboca en la afirmación por parte del caballo que todos los vecinos preferirían ver a En Buch sentenciado a muerte. En este momento el caballero se pregunta si por medio de la penitencia sus delitos podrán ser absueltos. El animal se ofrece a escuchar

\footnotetext{
14 En este caso no se trataría de fabliaux porque no son narraciones en verso, pero por su contenido humorístico los incluimos en este apartado.

15 Este códice contiene obras en verso como la Faula de Guillem de Torroella, El Blandín de Cornualla, el Libre dels Set savis de Roma, el Llibre de tres atribuido a Turmeda, la Disputació de nos ocupa y una serie de textos anónimos en verso que constituyen pequeñas narraciones de tema cortesano.

16 Blandín de Cornualla i altres narracions en vers dels segles XIV i XV, edición de A. Pacheco, Barcelona, Edicions 62 / La Caixa, 1983.

17 Según M. Marco: «l'autor anònim ens presenta el model de confessor, el que caldria trobar, però, donades les circumstàncies de l'època, no hi és dins de l'àmbit eclesiàstic un confessor d'aquesta mena, només un animal, en aquest cas, pot ser-ho». M. Marco, «La comicitat, la paròdia i aspectes anticlericals en alguns contes plaents catalans: La disputació d'en Buc ab son cavall i el Testament de Serradell de Vic», SCRIPTA, Revista internacional de literatura i cultura medieval i moderna, 2 (2013), pp. 1- 12.
} 
la confesión, que en realidad es todo un listado de crímenes relacionados con robos a mercaderes, caminantes y clérigos que tampoco suponen un gran enriquecimiento ya que las cosas robadas son gallinas, zapatos, mantas, abrigos... También confiesa que jamás aprendió oficio alguno excepto el robar y que hubiera preferido efectuar robos más considerables para enriquecerse.

El caballo le dice que debe devolver lo robado a lo que En Buch responde que no es posible porque no tiene prácticamente nada. En vista que esta penitencia no sirve, el caballo le propone ejercer el ayuno o rezar, pero En Buch ni está dispuesto a lo primero ni tampoco conoce ninguna oración (salmos, pater noster, avemarias...): ${ }^{18}$

-Si no quereis hacer caridad,

en Buch, ni quereis ayunar,

os conviene decir oraciones

y rezad a Dios arrodillado

-¿Eso te digo, caballo, qué haré?

-¿Qué oraciones diré?

- ¿No sabéis los Salmos de David?

-¿Cómo los sabré si no me los han dicho?

-¿No conocéis los salmos penitenciales?

-Si los supiera me tendría por vil y falso

-¿Y el padrenuestro, no lo sabéis?

-Si lo supiera, colgado me veríais

- ¿No sabéis el Avemaría?

-Si lo supiera, perdería la vida

-¿No sabéis el Credo?

-Si lo supiera, que todo cuanto tengo sea tuyo

-¿No sabéis ninguna oración?

-No caballo, que Dios me perdone

- ¿Y cómo habéis vivido así?

-De pan, de carne y de vino ${ }^{19}$.

18 Traducción al texto: «Pus que almoina no volets far, / En buc, ne volets dejunar, / digats doncs oracions / e pregats Déus a jonollons». / Això et dic, cavall que faré: / Mas quals oracions diré? / «No sabets los psalms de Daviu? / «E co ls sabré si anc no els viu?»/ «No sabets los psalms penitencials? / «Si els sé , tin-me per aul e per fals.»/ «No sabets lo Pater nostre?»/ «No sabets lo Credo en Déu? »/ «Si el sé penjat sies tui...» / «No sabets Salvum me fac?» / «Si el sé, quem tolgues lo cap.» / «No sabets nulla oració?/ «No cavall, si Déus me perdó.» / «E com havets viscut així?»/ «De pa e de carn, e de vi.» «Si el sé, tot quant he sia vostre.» / «No sabets l'Ave Maria?» / «Si la sé, cavall, mort m'aucia. / Si embla moltó o vedell, / dar-n'he lo ventre, mas no la pell / si embla gallina o capó / la ploma e els budells ne do/ de tot peix daré l'escat,/ e no en cerquets altra barata».

19 Blandin de Cornualla, ed. cit., p. 199-200. 
Finalmente se le ocurre hacer penitencia repartiendo parte de las cosas robadas de esta manera:

$$
\begin{aligned}
& \text { Si robo un cordero o un ternero } \\
& \text { daré el vientre pero no la piel, } \\
& \text { si robo una gallina o un capón } \\
& \text { la pluma y los intestinos daré. } \\
& \text { Del pescado daré las escamas } \\
& \text { y no busques nada más que baratarme. }{ }^{20}
\end{aligned}
$$

Ante tal penitencia el caballo no puede absolver a En Buch y le propone hacer testamento, pero lo único que puede dejar a su hijo son sus deudas y pecados. Por otra parte, dispone que su alma vaya al Montgibell, el infierno, y no al paraíso, porque no conoce ese lugar. Una vez hecha la confesión general y preparada su alma, el caballero puede morir en paz, pues se considera que sus pecados han sido expiados. Esta última parte del poema narrativo se convierte, pues, en una parodia de las artes moriendi de la época en las que se disponían los aspectos prácticos a aplicar al moribundo para un tránsito en paz. Falta en el caso de En Buch el sacramento de la extremaunción, de imposible aplicación porque al fin y al cabo su alma va al infierno.

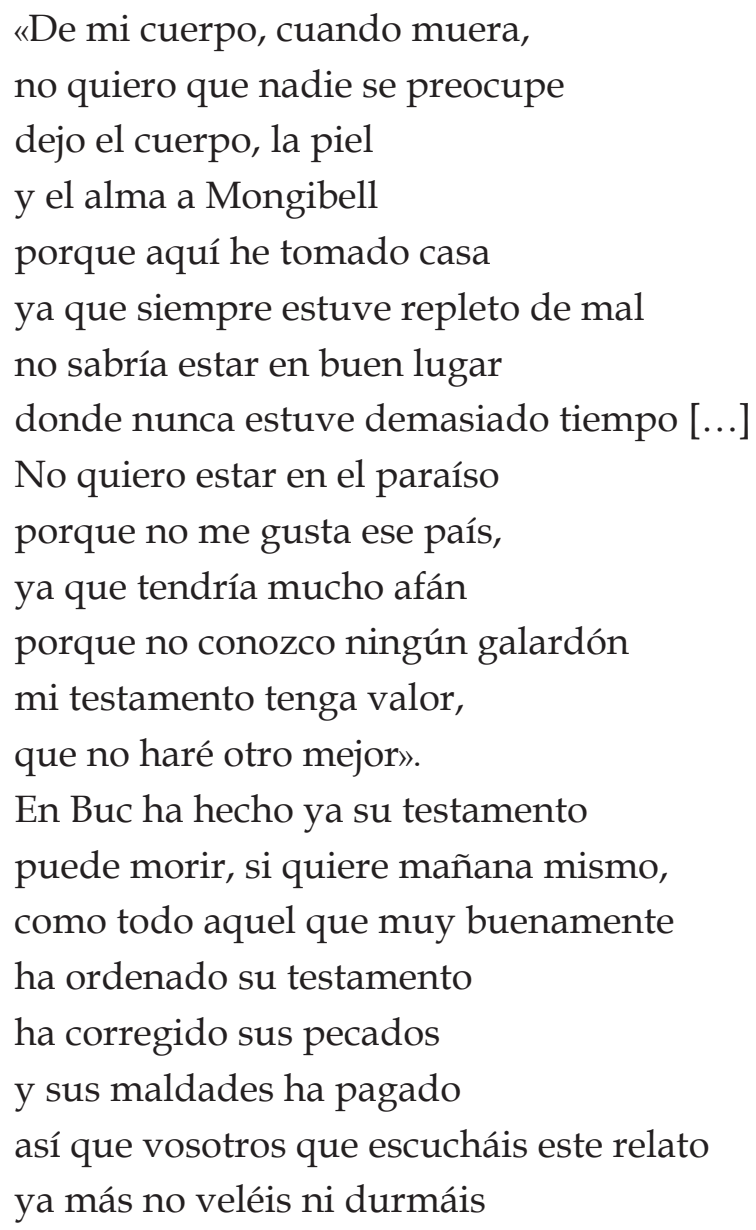

«De mi cuerpo, cuando muera, no quiero que nadie se preocupe dejo el cuerpo, la piel y el alma a Mongibell porque aquí he tomado casa ya que siempre estuve repleto de mal no sabría estar en buen lugar donde nunca estuve demasiado tiempo [...]

No quiero estar en el paraíso porque no me gusta ese país, ya que tendría mucho afán porque no conozco ningún galardón mi testamento tenga valor, que no haré otro mejor».

En Buc ha hecho ya su testamento puede morir, si quiere mañana mismo, como todo aquel que muy buenamente ha ordenado su testamento ha corregido sus pecados y sus maldades ha pagado así que vosotros que escucháis este relato ya más no veléis ni durmáis

20 Blandin de Cornualla, ed. cit., p. 200. 
y no hagáis vaguerías

leyendo este libro tanto como podáis. ${ }^{21}$

La parodia de la liturgia religiosa y las argucias del caballero para evitar las acusaciones o la penitencia impuesta son los elementos cómicos más destacables de esta breve narración en la que el animal adquiere el papel de sacerdote, es decir, intermediario entre Dios y los hombres con la capacidad de perdonar los pecados e imponer penitencia. Sin embargo, el caballo tampoco es un modelo, no tiene una buena reputación, ya que recordemos que al inicio de la obra también había una acusación contra él y, aunque aparentemente adquiere un papel serio, no hay que olvidar que es un confesor bastante desacreditado, ladrón y golafre, que pretende dar una penitencia sin conseguirlo aunque al final se muestra de acuerdo con la decisión del caballero, por lo que la ridiculización aún es mayor.

\section{EL ASNO}

Las apreciaciones ridículas del asno doméstico, motivo de burlas festivas, figuran en la descripción del animal que realiza el naturalista Bartolomaeus Anglici: ${ }^{22}$ bestia perezosa, sin entendimiento, simple y retrasada, de aspecto deforme y formas viles que se alimenta de espinas y cardos. Por otra parte, los bestiarios y los tratados enciclopédicos medievales no incluyen al asno doméstico, en cambio sí que es habitual encontrar el salvaje, un animal de connotaciones negativas: perezoso, extremadamente lujurioso e, incluso, considerado una figura diabólica.

El asno se asemeja al animal miserable y burlesco de las fiestas transgresoras conocidas como las Libertates decembris, que coinciden con el ciclo festivo Navideño. Entre otras manifestaciones en catalán, encontramos el Sermó del Bisbetó y la Festa de l'Ase. El dia 6 de diciembre, festividad de San Nicolás, se elige un niño que será investido como obispo (bisbetó= ‘pequeño obispo’) quien el día de los Inocentes, 28 de diciembre, pronunciará un sermón de crítica social a lomos de un asno, conocido

21 Blandin de Cornualla, ed. cit., p. 201. «De mon cors, con será mort, / no vull que hom se'n treball fort, / eu lleix lo cors e la pell / e l'ànima a Mongibell, / car aquí he pres hostal, / que tostemps fui vesat de mal, / no sabría estar en bon lloc / que tostemps estigui poc [...] / no vull estar en paradís / car no m'asalta son país, / car trop n'hauria gran afany / pequè no hi conec null gasany. / Mon testament haja valor / que no en faré altre millor.» / En Buc son testament fet ha / morir-se pot, si es vol, demà / així com cell qui bé e gint / ha ordonat son testament / e sos pecats be esmenats / e tots sos torts fort bé pagats. / Perquè vós, qui açò escoltats, / ja més no vetlets ne dormats / ne no posets ne vaguets llegint est llibre tant pusquets.

22 La obra de este naturalista, De proprietatibus rerum, contiene en su libro 18 las descripciones sobre animales. La enciclopedia, redactada en el siglo XIII, supuso una importante fuente para tratados naturalistas posteriores. Hemos consultado el facsímil del incunable de Nuremberg de 1492. Disponible en http://d3seu6qyu1a8jw.cloudfront.net/sites/default/files/collections/32/324D849D-5D6C-4FC5B8F4-390AF48ECA45.pdf [consultado 04-06-2015]. 
como el Sermó del Bisbetó, del cual se conservan dos versiones. ${ }^{23}$ Respecto a la Festa de l'Ase, se celebraba el primer día del año e intentaba ser un recuerdo de la Huida a Egipto de la Sagrada Familia a lomos de un asno, con cantos profanos e imitaciones de la voz del animal para mayor diversión. Estas representaciones, como es de suponer, se eliminaron en la Contrarreforma. ${ }^{24}$

No es de extrañar, por lo tanto, que el asno sea motivo de burla en proverbios y ejemplos, de forma que comparar un ser humano con este animal represente el punto más ínfimo de la escala de valores. Este papel viene de la antigüedad y es representativo en el Asno de Oro de Apuleyo, obra bien conocida en la que un personaje, a causa de los sortilegios que practica se convierte en un asno y con esta figura es menospreciado y apaleado pero que también le permite observar a su alrededor y criticar lo que observa.

Retomamos en este punto dos breves cuentos de Francesc Eiximenis, utilizados como ejemplos del debate pro y antifemenino. En el primero, una somera, la hembra del asno, pretendía embellecerse para el día de su boda y, para esto, contrata los servicios de una mujer experta en belleza, tal como ha visto hacer a su ama. La burrita se somete a sacrificios como la depilación facial que le produce un inmenso dolor, de manera que prefiere abandonar esta práctica y presentarse tal como es ante su futuro esposo, criticando de esta manera los cuidados corporales y cosméticos a que se someten las mujeres con el único fín de engañar con esta supuesta mejorada apariencia cuando en realidad no es la natural.

En el segundo cuento, la hembra del asno adquiere un carácter positivo ya que rechaza los requerimientos amorosos del lobo y no desea ser como las mujeres que tienen varios amantes para burlarse de ellos, porque al final, quienes acaban burladas y sucias son las propias mujeres. En este caso, el lobo cambiará de opinión y elogiará el buen sentido y sabiduría que demuestra la burrita. ${ }^{25}$

Si seguimos con ejemplos positivos, el más conocido proviene del pasaje bíblico del asno de Balam en el que el animal es capaz de percibir antes que los hombres el ángel enviado por Dios con la finalidad de combatir la ira de Balac contra el pueblo de Israel (Números, 22: 23-31), un pasaje que Turmeda recuerda en la prueba segunda en

\footnotetext{
${ }^{23}$ Podemos leer una de estas versiones actualizadas en Blandín de Cornualla $i$ altres narracions en vers dels segles XIV i XV, edición de A. Pacheco, Barcelona, Edicions 62 / La Caixa, 1983, pp. 192-193. También J. Romeu i Figueras, «Els dos textos catalans del Sermó del Bisbetó», en R. Alemany et al. Actes del Novè Col loqui Internacional de Llengua i Literatura Catalanes I, Barcelona, Abadia de Montserrat, 1993, pp. 189231.

24 J.F. Massip, Història del teatre català. Dels origens a 1800, Barcelona, Arola, p. 98

25 F. Eiximenis, Contes i faules, Barcelona, Barcino, 1925, pp. 140-142 y 156-157.
} 
boca del asno, precisamente para destacar la perfecta visión de estos animales, superior a la del hombre: ${ }^{26}$

Vous verres davantage, frère Anselm, si vous lisez au Chap. 22 du livre des Nombres traictant de l'asnesse du prophète Balaam, quand le roi Balac l'envoya pour mauldire le peuple d'Israël. Et nostre seigneur Dieu envoya son ange, avec l'espée en sa main, affin qu'il ne le laissast passer plus oultre, parquoy l'ange se mist au millieu du chemin. Et voyant l'asnesse l'ange dobut avec l'espée, eut peur et se arresta. Et le prophète ne voyant point l'ange donnoit des esperona à ladicte asnesse pour la faire passer oultre. Et elle ne pouvant souffrir l'injure que ledict prophète luy faisoit, luy peránt les costex avecques les esperons, dict: «Mon seigneur, pourquoy me talonnes-tu ainsi? As-tu jamais veu que je $t^{\prime}$ aye faict chose semblable? Tu me bats pour ce que je ne passe oultre, et je ne puis passer pour l'empeschement de la voye». Là, dict le Texte, frère Anselme que nostre seigneur Dieu ouvrit les yeux audict prohète; et en regardant, il vit l'ange, et incontinent luy dict: «Pardonne-moy, car je ne sçavoye pas que tu fusses icy». Et l'ange luy dict: «Si n'eust esté que l'asnesse s'est arrestée, je t'eusse tué». Et après luy commanda de par Dieu qu'il ne maudist pas le peuple d'Israël [...]

En definitiva, es un animal que, desde su baja posición es capaz de dar una lección de humildad al hombre que se cree superior a las otras bestias, un argumento $a$ contrario que suele ser efectivo y utilizado en múltiples textos animalísticos, sobre todo en los bestiarios.

\section{Anselm Turmeda y la Disputa de L'Ase}

Situamos la producción Anselm Turmeda a finales del siglo xIV e inicios del $\mathrm{XV}$, una época caracterizada por la escasa literatura de ficción, si bien fecunda para la literatura didáctico-doctrinal. La Corona de Aragón, gobernada por Pedro el Ceremonioso, institucionaliza la cultura en un proceso político que vino a superponer otras necesidades literarias a la pura ficción del entretenimiento. ${ }^{27}$ El rey Pedro fue gran amante de las letras, promovió la traducción de la obra historiográfica de su precedesor Jaime $\mathrm{I}^{28}$ marcó una política cultural con la promoción de diversas traducciones de textos clásicos de tipo práctico como por ejemplo tratados de agricultura o arquitectura,

26 A. Tumeda, Dispute de l'âne, édition critique d'Armand Llinarès, Paris, Vrin, 1984, p. 59.

27 Alemany, R. (1997), «El context literari i intel-lectual de la Corona d'Aragó en 1'època de sant Vicent Ferrer», dins Paradigmes de la història, I: Actes del Congrés Sant Vicent Ferrer i el seu temps (València, 1996), Valencia, Saó, pp. 47-70.

28 Se trata del segundo manuscrito más antiguo de la obra historiográfica de Jaume I, el Llibre dels Feyts, que se conserva en la Biblioteca de Catalunya con el número 1734, y que indudablemente corresponde a la Cancilleria de Pere III el Cerimoniós. Este rey mandó copiar la Crónica de su antepasado a uno de sus oficiales, Joan de Barbastre, quien lo acabó el 1380, tal y como consta en la documentación generada relativa al plazo de trabajo, los pagos al copista, reproducidos por A. Rubió i Lluch Documents per a l'història de la cultura catalana mig-eval, 2 vols., Barcelona, IEC, 1908 [reproducció facsímil amb estudi sobre A. Rubió d' Albert Balcells i pròleg d'Albert Hauf, Barcelona, IEC, 2000], vol. II, p. 295. 
entre otros, ${ }^{29}$ pero sobre todo contó con un admirable colaborador, Francesc Eiximenis, para desempeñar una gran tarea: la «recristianización» de las instituciones ciudadanas en aras a una mejor convivencia.

Este ambiente cultural es el propicio para una producción prosística de carácter doctrinal, autores como el propio Eiximenis y su magna obra Lo Crestià; ${ }^{30}$ el predicador por antonomasia, Vicent Ferrer; autores de talante devocionalista como Antoni Canals, ${ }^{31}$ quien advierte del peligro que supone la irrupción de la interpretación de los clásicos que se está produciendo en Europa y que se conoce como Humanismo. Sin embargo, al lado de estos autores religosos ortodoxos, surge otra forma de pensar gracias al acceso a la cultura por parte de una élite de intelectuales laicos, ${ }^{32}$ de los cuales el más relevante es Bernat Metge, personaje tremendamente complejo que en su obra se atreve a cuestionar principios de la religión cristiana de una manera sutil y tomando como autoridad los clásicos.

Ansem Turmeda puede relacionarse en cierta manera con esta forma de pensar si bien las peripecias de su vida nos acercan a un personaje contradictorio con una fuerte personalidad y extremadamente hábil. Turmeda fue un franciscano que se convirtió al Islam y que desde su nueva perspectiva -con la comodidad que le proporciona la lejanía- y en un tono satírico se atreve a cuestionar en su obra Disputa de l'Ase ciertos principios cristianos que escandalizarían a los más ortodoxos, si bien su ideario concluye con una cierta aceptación en tono de burla de la esencia de la religión cristiana. ${ }^{33}$ No es

\footnotetext{
29 J. N. Hillgarth, «La personalitat política i cultural de Pere III a través de la seua crònica», Llengua $\mathcal{E}$ Literatura, 5 (1993), pp. 7-102.

30 Lo Crestià se puede considerar un compendio o summa de lecciones para la vida de un buen cristiano: contiene descripciones de los principios básicos del cristianismo, de virtudes a practicar, una extensa reflexión sobre el origen del mal y cómo evitar los pecados. Se puede decir que intenta abarcar todos los aspectos de la vida cristiana con la novedad que el tratado pretende, por medio de esta vía de cristianización, promover el orden social, no en vano la obra está pensada para las nuevas clases que surgen de la consolidación de las ciudades. Lo Crestià se concibió como 13 volúmenes de los que sólo se llegaron a escribir 4: el Primer, Segon i Terç del crestià, por una parte, y el Dotzé, destinado a los gobernantes y que constituye un auténtico tratado de organización política ideal siguiendo los principios cristianos: A. G. Hauf, D'Eiximenis a sor Isabel de Villena. Aportació a l'estudi de la nostra cultura medieval, València-Barcelona, PAM-IFV, 1990.
}

31 G. Avenoza, «Traducciones Valerio Máximo en la Edad Media Hispánica», en Reflexiones sobre la traducción. Actas del Primer Encuentro Interdisciplinar «Teoría y práctica de la traducción» (Cádiz, 29 marzo- 1 abril de 1993), ed. L. Charlo Brea, Cádiz, Servicio de Publicaciones de la Universidad de Cádiz, 1994, pp. 167-180. F. Rico, «Antoni Canals i Petrarca. Para la fecha y las fuentes de Scipió i Anibal», en Miscel lània Sanchis Guarner, III, Barcelona, PAM, 1992, pp. 53-63.

32 L. Badia, De Bernat Metge a Joan Roís de Corella. Estudis sobre la cultura literària de la tardor medieval catalana, Barcelona, Quaderns Crema, 1988. S. M. Cingolani, El somni d'una cultura: Lo Somni de Bernat Metge, Barcelona, Quaderns Crema, 2002.

${ }_{33}$ La biografia de Turmeda es realmente interesante. Nace en Mallorca aproximadamente a mitad del siglo XIV, ingresa en la orden franciscana y durante una discusión con sabios de Bolonia sobre la figura del Paracleto -el enviado posterior a Jesucristo-, aceptó la religión musulmana y a su profeta. No se sabe exactamente lo que motivó la conversión pero después de instalarse en Tunez tuvo diferentes ocasiones 
la única obra de Turmeda en la que parodia preceptos cristianos. En su Llibre de bons amonestaments, el autor realiza un contrafactum de sermón en el que uno de los episodios más relevante es el elogio al dinero, junto a otros motivos goliardescos. ${ }^{34}$

No olvidemos que en todo este panorama cultural en el que confluyen la ortodoxia más recalcitrante con nuevos aires procedentes de los humanistas, hay un hecho que propició todas estas discusiones religiosas: la gran crisis espiritual creada por el Cisma de Occidente y que condicionó la política de los estados medievales, siendo la Corona de Aragón uno de los mayores partidarios del papado de Aviñón y argumento de una de las profecías del asno de la Disputa.

La Disputa de l'Ase se escribió probablemente el 1417 o 1418, cuando su autor, Anselm Turmeda, ya convertido al Islam, residía en Túnez desde hacía varios años. El hecho de continuar utilizando el catalán en su obra nos lleva a pensar en un hipotético interés por dar a entender su vinculación con las raíces mallorquinas que no habría olvidado, y la esperanza por volver. Ahora bien, el tema de la Disputa y la agilidad con la que trata temas ortodoxos, no parece indicar que fuera bien acogida en la sociedad cristiana de la época. En cualquier caso, Turmeda, desde su conversión, siempre marcó esta diferencia y con habilidad intentó hacer creer a sus antiguos colegas que había cometido un error, mientras que por otra parte, se congratuló con la élite musulmana escribiendo su última obra en árabe donde justifica su conversión y ataca los errores del cristianismo.

El texto catalán de la Disputa no se conserva, aunque hay referencias a una edición catalana antigua de 1509 que se perdió por ser incluida la obra en el índice de libros prohibidos de Madrid de 1583. Se conservan varias ediciones de una traducción francesa, la primera de Lyón, sin fecha, una segunda de 1548 (base de la edición crítica de Armand Llinarès de 1984) y otra de París 1606. De esta forma, el texto más cercano al original actualmente son estas traducciones francesas, ya que las ediciones catalanas modernas son reconstrucciones.

de reincorporarse a su origen cristiano pero los intentos fueron en vano. Su obra catalana, escrita en Túnez contiene diversas alusiones a su origen y situación después de abrazar el Islam, su consideración de sabio entre la nueva élite que frecuentó y sus juegos de perspectivas que le facilitaron la escritura de unas obras en las que se permitía distanciarse cómodamente de la ortodoxia cristiana: R. Alemany, «Presències i ecos d'un jo individuat en l'obra d'Anselm Turmeda», ELLiLC, XXIX (=Miscel lània Germà Colón, 2), 1994, pp. 5-24; R. Alemany, «Tradició i innovació literaria en la Disputa de l'Ase d'Anselm Turmeda», en Professor Joaquim Molas; memòria, escriptura, història, 2 vols., Barcelona, Publicacions de la Universitat de Barcelona, 2003, I, pp. 15-26. M. de Epalza, Fray Anselmo Turmeda (Abdallah al-Taryuman) y su polémica islamo-cristiana. Edición, traducción y estudio de la «Tuhfa», Madrid, Hiperión, 1994.

34 R. Alemany, «Rex est hoc tempore nummus: un motiu goliardesc reciclat per l'Arcipreste de Hita i per Anselm Turmeda», en R. Alemany / F. Chico, eds. Literatures ibèriques medievals comparades = Literaturas ibéricas medievales comparadas, Alacant: Universitat d'Alacant; Sociedad Española de Literatura General y Comparada, 2012, pp. 39-51. 
La obra comienza con un encuentro casual entre el protagonista y un grupo de animales que están debatiendo la elección de un nuevo rey, puesto que el anterior ha muerto sin descendencia (clara alusión al compromiso de Caspe después de la muerte sin herederos legítimos de Martín I que culminó con la entronización de Fernando de Antequera). El inicio nos recuerda también al Llibre de les Bèsties de Ramon Llull, si bien el conflicto a dilucidar en la obra lulliana es la conveniencia de encontrar un rey entre los animales carnívoros o herbívoros, hecho que dará pie a las intrigas de la zorra $\mathrm{Na}$ Renard y la concatenación de ejemplos, algunos procedentes como ya sabemos, del Kalilah wa-Dimna.

El debate para la elección real de la Disputa turmediana se cierra con la proclamación, a propuesta del caballo, del hijo de un primo hermano del león difunto, el llamado «Lyon roux de la longue queue». Nuestro protagonista es descubierto por los animales quienes le identifican rápidamente como Frère Anselm, natural de Mallorca, convertido al Islam y oficial de la aduana de Túnez, pero sobre todo conocido como defensor de la superioridad del hombre sobre los animales, criaturas de Dios. Los animales no están de acuerdo con esta afirmación y proponen que por medio de una disputa con ellos reúna razones de peso para confirmar esta afirmación. El animal encargado de disputar con Frère Anselm es el «Asne roigneux à la queue coupée», el más miserable e indigno de todos los animales, ante el cual el hombre se burla si bien pronto demostrará sus cualidades dialécticas.

El inicio de la obra muestra un alto grado de ironía, característica esta que no aparece en la posible fuente de Turmeda, la obra de los Ihwan as Safa (Hermanos de la Pureza), Disputa de los animales contra el hombre, un apólogo incluido en la enciclopedia que elaboró esta comunidad Shií de Basora en el siglo VIII. ${ }^{35}$ La disputa árabe tiene como tema central la superioridad del hombre frente a los animales en un tono erudito, y encontramos ciertas concomitancias que, posiblemente, Turmeda recogió en el tratamiento de algunas cuestiones y en los argumentos razonados que se dirimen. Sin ir más lejos, los asnos que aparecen en la disputa árabe no tienen relación con el del texto catalán de Turmeda. Son modelos de discreción y sumisión al hombre, con un componente positivo.

Las disputas medievales románicas tienen como tema de debate otras cuestiones más banales ${ }^{36}$, y no es hasta el Renacimiento cuando se plantea la cuestión de la

35 M. Asín Palacios, «El original árabe de la Disputa del Asno contra fray Anselmo Turmeda», Revista de Filología Española, I (1914), pp. 1-51. Contamos con una traducción de este apólogo, E. Tornero Poveda, trad. La disputa de los animales contra el hombre (traducción del original árabe de la Disputa del asno contra fray Anselmo Turmeda), Madrid, Universidad Complutense, 1984.

36 La lírica trovadoresca contiene numerosos ejemplos de debates entre trovadores, uno de los más recordados es el que mantienen Bertran de Born y Raimbaut de Aurenga sobre la conveniencia de utilizar 
dignidad humana. ${ }^{37}$ Sin embargo, existen en la literatura griega una serie de obras que presentan discusiones entre asnos y hombres, como por ejemplo, poemas satíricos bizantinos con protagonistas animales que Turmeda podría conocer en su estancia a Italia, antes de su conversión al Islam. ${ }^{38}$

El contenido de la Disputa turmediana lo conforman diecinueve pruebas por las que Frère Anselm intenta demostrar la mayor dignidad de los hombres pero que son rebatidas facilmente por el asno, algunas con una brutalidad pasmosa, otras con una sutileza de conocimientos teológicos y naturalistas que demuestran el grado de cultura que había conseguido su autor. No obstante, predomina la ridiculación en aquellas afirmaciones que intentan demostrar que el hombre es superior con argumentos aparentemente banales como:

- Prueba 1. La bella semblanza de los hombres y su proporción. El asno rebate la afirmación aludiendo a la forma concreta de cada especie animal, adaptada a sus necesidades.

- Prueba 3. Los hombres prefieren la rectitud y justicia, mientras que los animales no conocen este principio. El ejemplo más relevante es de las abejas y su rey, modelo de justicia y orden social.

- Prueba 4. Los hombres comen manjares delicados, sin embargo existe una larga serie de enfermedades que se generan por comer demasiado.

- Prueba 5. Los hombres son capaces de construir instrumentos con los que obtener placeres, como la música. El asno responde que las alegrías en vida se convierten en pena en los funerales.

- Prueba 7. Los hombres llevan buenas vestimentas, sin embargo esos vestidos provienen de los animales, como la lana o la seda

- Prueba 8. Los hombres tienen gobernantes y consejeros. Los animales también tienen reyes y más justos porque los gobernantes de los hombres solo se preocupan de sacar provecho de sus súbditos, impuestos, tributos injustos, corrupción, etc.

un estilo sencillo en las composiciones poéticas o un «trobar clus», considerando la poesia una actividad culta y elitista. Aparte de temas banales como el debate sobre el verano o el invierno, el agua o el vino, el caballero o el clérigo, proliferaron una serie de temas de discusión como los debates entre el cuerpo y el alma, tema que reencontramos en la poesía número 4 de Ausiàs March. Otro gran tema de discusión escolar fueron los debates pro y antifemeninos que se plamarosn en obras como el Matheolus, La Cité des Dames y en la literatura catalana, Lo Somni de Bernat Metge o el Spill de Jaume Roig.

37 R. Alemany, art. cit., 2003, pp. 15-26.

38 J. Redondo, «Les posibles fonts gregues de la Disputa de l'ase de Fra Anselm Turmeda», en C. Bosch \& P.J. Quetglas (eds.), Mallorca i els clàssics, II Ciutat de Mallorca, 2000, pp. 33-48. 
- Prueba 10. Los hombres alimentan y cuidan de los animales. El asno responde que no es un cuidado desinteresado ya que la muerte de un animal provoca pérdidas económicas en su propietario

- Prueba 11. Los hombres son capaces de construir hermosos edificios. Esta afirmación es fácil de rebatir por el asno con los ejemplos de la abeja o de la tela de araña, construcción sutil.

- Prueba 12. Los hombres se alimentan de animales. Llegado este momento, el debate se amplia a otros interlocutores e intervienen los insectos y parásitos que viven en el cuerpo humano para llegar al máximo de ridiculización. Se trata de los mosquitos, pulgas, chinches, piojos y un curioso gusano que no es más que la bacteria de la caries, por lo que se deduce que Turmeda perdió su dentadura. ${ }^{39}$

- Prueba 15. Los hombres tienen órdenes religiosas. En este apartado se incluyen siete narraciones anticlericales que demuestran la falsedad de los religiosos. Por su comicidad y elaboración se consideran los primeros cuentos de inspiración boccaccesca en prosa.

- Prueba 17. Los hombres usan perfumes y son más limpios que los animales. Los productos cosméticos suelen ser de origen animal y de hecho hay tratados de cosmética que explican la composición de estos productos. ${ }^{40}$

Los argumentos más serios que propone Frère Anselm, aunque igualmente rebatidos por el asno son los siguientes

- Prueba 2. El hombre posee memoria y cinco sentidos más perfectos que los de los animales. Els asno rebate la afirmación con ejemplos de animales que poseen sentidos corporales más sutiles que el hombre: caballo el oído, el águila la vista, etc., e incluso animales con mayor memoria que el hombre como la golondrina y otras aves migratorias que recuerdan año tras año donse estan sus nidos.

- Prueba 6. Dios ha dado a los hombres una ley, se refiere a la religión, y ha enviado profetas. Según el asno, de la misma manera que los hombres poseen una ley, la violan con todos los pecados que cometen.

\footnotetext{
39 R. Alemany, «Insectes perspicaces dans une parodie des débats scolastiques», Reinardus. Yearbook of the International Reynard Society, 25 (2013), pp. 1-10.

40 M. I. Betlloch, et alii, «The use of animals in medicine of Latin tradition: study of the Tresor de Beutat, a medieval treatise devoted to female cosmetics», The Journal of Ethnobiology and Traditional Medicine, 121 (2014), pp. 752-760.
} 
- Prueba 9. Los hombres son creados a imagen de Dios quien les ha dado una fisionomia particular, la palabra y la escritura. El asno responde que si bien los hombres tienen una semblanza única -y esto recuerda a la primera de las pruebas- ciertamente las diferencias entre los hombres son irreconciliables y provocan múltiples guerras y desacuerdos, mientras que los animales, pese a las diferencias, son todos de un único pensamiento común.

- Prueba 13. El alma humana es inmortal. Esta prueba es la que se considera definitiva en la Disputa de los animales de los Hermanos de la Pureza y, podría considerarse también una prueba concluyente en la disputa cristiana. Sin embargo, y por sorpresa, el asno responde con dureza, criticando el escaso entendimiento de su contrario y rebate el argumento con la afirmación que la mayor parte de las almas humanas van a parar al infierno puesto que no conocen la gloria del paraíso.

- Prueba 14. Los hombres son creados a imagen y semblanza de Dios. Este argumento no aparece en la Disputa árabe por razones obvias, y aunque parece ser otra afirmación contundente, pues remite a un pasaje del Génesis, el asno rebate a Frère Anselm con la teoria del microcosmos humano. ${ }^{41}$ Según esta teoría el hombre posee en su cuerpo doce conductos que equivalen a los 12 signos; cuatro miembros a semblanza de los cuatro elementos naturales -fuego, tierra, aire y agua; además compara la parte anterior del cuerpo humano con los lugares habitados y la posterior con los desiertos. ${ }^{42}$

Davantage, la partie de devant du corps de l'homme et ainsi comme le lenvant, et le derrière est ainsi comme le ponent. La main dextre est comme la midy et la senestre comme le septentrion; l'esternuer, cryer, toussir, et le bruit et rumeur que font les boyauls sont comme les tonnerres, ainsi que dessus vous ay dict et declaré. Et les larmes, la salive et l'urine sont ainsi que la pluye; le rire est comme la clarté du jour, le plorer comme l'obscurité de la nuict; le dormir, comme la mort, le veiller, comme la vie; le temps de la puérillité, comme le printemps, l'adolescence, comme l'esté, la jeuneusse, comme l'automne, la vieillesse, comme l'yver. Et aussi, comme le grand monde est regy et gouverné par nostre Seigneur Dieu, ainsi le petit monde, c'est à sçavoir le corps de l'homme, est régy et gouverné et seigneurié par l'âme intellective.

${ }_{41}$ F. Rico, El pequeño mundo del hombre. Varia fortuna de una idea en las letras españolas, Madrid, Castalia, 1970, pp. 90-96.

42 Turmeda, ed. cit., 1984, p. 90. Traducción del texto: La parte delantera del cuerpo es como Levante, y la trasera, como Poniente. La mano derecha es como el mediodía, y la izquierda como el septentrión. El estornudar, gritar, toser y el ruido que hacen los intestinos son como las tormentas. Las lágrimas, la saliva y la orina como la lluvia. La risa, como la claridad del día, el llanto como la oscuridad de la noche; dormir como la muerte, el velar como la vida. El tiempo de la infancia como la primavera, la adolescencia como el verano, la juventud como el otoño y la vejez como el invierno. Y tambien como el macrocosmos o gran mundo está regido y gobernado por nuestro Señor, el pequeño mundo, es decir, el cuerpo del hombre, está regido y gobernado por el alma intelectiva. 
- Prueba 16. Los hombres poseen instinto natural e inteligencia, mientras que los animales solo un poco de discreción natural. En esta prueba, el asno va dando ejemplos de animales que se caracterizan por su buen entendimiento, la mayor parte de estos ejemplos proceden de los bestiarios y enciclopedias medievales y se trata del fragmento de la Disputa en que encontramos una mayor presencia de fuentes occidentales. ${ }^{43}$

- Prueba 18. Los hombres poseen diferentes ciencias, entre ellas la astrología y otras artes adivinatorias, a lo que el asno responde con una profecía apocalíptica ante el supuesto final del Cisma con la llegada de un nuevo Papa a Roma. ${ }^{44}$

La razón concluyente que da la victoria a Frère Anselm después de tantas situaciones ridículas y de ser vilipendiado por el asno es la número 19, que hace referencia al misterio de la Encarnación divina en un hombre, y que por supuesto no aparece en el texto árabe.

El asno, alter ego del autor, se convierte en el auténtico ganador de la Disputa, demostrando sus conocimientos y despreciando a su interlocutor con alusiones a su escaso razonamiento y a su grosería. ${ }^{45}$

Frère Anselm, ouyant la renommée de vostre science et sagesse qui volle par toute ceste province, abant que je vous cogneusse ny vous eusse auy parler, sçachez que je vous tenoys en grande réputation et sagesse; mais à present trouvant le contraire, vous tiens pour une rude et lourde personne.

Hé frère, hé frère, penser avant que parler c'est sagesse; et vous faictes le contraire qui parlez devant que penser, et cela est grande et haultaine follie meslée avec plus grande ordure. ${ }^{46}$

A consecuencia de estas intervenciones, Frère Anselm reacciona y se da cuenta que está perdiendo el debate ante un contrario tan inferior por lo que replantea la estrategia, sin éxito a veces, o bien, el propio asno es quien le ayuda a salir de la situación embarazosa invitándole a continuar con la disputa.

${ }_{43}$ M. Garcia y L. Martín, «Algunes fonts occidentals de l'obra d'Anselm Turmeda Disputa de l'ase», Revista de Filología Románica, 13 (1996), pp. 181-214, especialmente pp. 198-209. También L. Martín, «La Disputa de l'ase d'Anselm Turmeda i la tradició enciclopèdica medieval», dins Juan Paredes (ed.), Medioevo y literatura. Actas del V Congreso de la Asociación Hispánica de Literatura Medieval (Granada, 1993), III, Granada, Universidad de Granada, 1995, pp. 213-227.

44 J. Pou i Martí, Visionarios, beguinos y fraticelos catalanes (siglos XIII-XIV), estudi preliminar d'Albert Hauf i Valls, Alacant, Instituto de Cultura Juan Gil-Albert, 1996 [1930].

45 Turmeda, ed. cit, 1984, p. 58. Traducción al texto: Frère Anselm, oyendo lo renombrado de vuestra ciencia y sabiduría que se conoce en toda esta provincia, antes que yo ous conociese ni ous hubiese oído hablar, sabed que os tenía en muy gran aprecio y reputación, pero ahora encuentro que es todo lo contrario y os tengo por una persona ruda y grosera de entendimiento

46 Turmeda, ed. cit, 1984, p. 62. Frère Anselm, quien habla mucho, continuamente se equivoca... Me parece que estáis un poco dulce de sal y ligero de peso 
¿Qué pretende Turmeda? La comodidad de la forma elegida, el debate, permite cuestionar principios de la religión cristiana que él había abandonado varios años antes en boca de un ser ridículo como burla o advertencia a las clases más ortodoxas de la posibilidad de una nueva forma y diferente de interpretar las verdades o dogmas religiosos, todo esto en una época de crisis y desde una nueva situación personal, de lejanía y conversión a l'Islam de su autor. No obstante, el juego de Turmeda se hace aún más irónico cuando decide dar la victoria al personaje humano aludiendo a la Encarnación divina en un hombre. Quizás Turmeda no olvidaba que le convenía congraciarse con sus antiguos correligionarios o bien la ridiculización es aún mayor ya que da la razón aludiendo a un misterio del cristianismo, sin embargo jamás regresó de Túnez ni revocó su conversión. Recordemos que su conversión al Islam fue también objeto de una obra escrita en árabe, el Presente del hombre letrado contra los partidarios de la cruz, conocida como la Tuhfa, si bien explotada hasta la saciedad por la sociedad musulmana. ${ }^{47}$

En la prueba 15 el asno se convierte en un contador de cuentos ágil y divertido. En total son siete narraciones las que pronuncia para demostrar los pecados capitales de los clérigos. Estos cuentos van dirigidos directamente a su interlocutor, Frère Anselm, pero pronunciados delante de la concurrencia de todos los animales, más aún el rey de los animales, el recientemente elegido león, es quien le pide formalmente al asno que cuente las narraciones sin temor a ser prolijo ya que es importante para el desarrollo del debate conocer todas las pruebas de la indignidad humana.

El más conocido de estos cuentos es el relativo a la lujuria de los clérigos mediante una ridiculización del sacramento de la confesión (tema ya tratado en la Disputació d'en Buch ab son cavall però ahora desde una perspectiva diferente y centrándose en el pecado de lujuria). En concreto, la narración que nos ocupa presenta un fraile joven a quien acude una mujer bella pero con escaso entendimiento «dolça de sal», enviada por su marido para que se confiese en tiempo de Cuaresma. La mujer, llamada Madona Tecla, es muy simple e inmediatamente es engañada por el fraile, Joan Juliot, quien haciendo gala de una enorme lascivia la convence de que para absolverla de sus pecados debe hacer el amor con su confesor una vez de cada diez que lo hace con su marido. La confesión consiste, pues, en el recuento por parte de la joven y del confesor de sus contactos sexuales y el «cobro» de esta especie de impuesto por parte del religioso.

Otro cuento menos conocido, por ejemplo, es el referido a la gula. La amiga de un sacerdote, Caterina, cocina un buen pastel de pescado para el día de Navidad y le dice a su protector que lo coman rápidamente porque pueden llegar extraños a

47 M. de Epalza, op. cit., 1994. 
la casa y quedarse sin su banquete. Efectivamente varios religiosos que conocen las habilidades de la cocinera se presentan en la casa, por lo que ella esconde el manjar y les ofrece siete sardinas. Los religiosos saben que ha escondido la comida y le hacen creer, cogiendo una sardina y poniéndosela a la oreja, que esta habla y les dice que en la casa hay un pescado mucho más grande y suculento que está escondido. Ante tal revelación, Caterina saca el majar y lo reparte con los religiosos.

El componente irónico y divertido de estas dos narraciones desaparece en otras de la colección. El cuento sobre la soberbia tiene un argumento trágico, centrado en la persona cruel del gran abad de Perusa quien se dedica a perseguir bellas mujeres y a disculpar a los clérigos que hacen lo mismo. La tragedia se produce con la muerte de la esposa de Joan Ester, quien se suicida, embarazada de ocho meses, para evitar la lascivia de un clérigo protegido por el gran Abad. El marido pide justicia; sin embargo, el gran Abad acusa de blasfemia al clérigo causante de la desgracia. Joan Ester viaja a Florencia con el cuerpo de su hijo embalsamado donde se genera una rebelión general contra la Iglesia y sus abusos de manera que por la muerte de la esposa es hecha justicia.

De esta forma, el asno de la Disputa se revela como un experto narrador, la concatenación de los cuentos sigue un curso lineal, y aunque un cuento lleva a otro no se llega a generar una estructura de cuentos dependientes de otros. En el transcurso de los cuentos, el asno interpela varias veces a su interlocutor en un intento de captar su atención continuamente, mientras que el personaje de Frère Anselm interviene una vez para reconocer la sutileza de su contrincante y pedirle que continúe con las narraciones. ${ }^{48}$

\begin{abstract}
Seigneur Asne, selon le proverbe: «Maulvais chappe coeuvre souvent bon beveur», ainsi me semble-t-il de vous. Car qui vous voit ainsi maigre, escorché et sans queue, il pense qu'en vous n'ayt nulle subtilité, mais que vous soyez lourd et idiot, combien que à ce que je voy, vous estes ung grand taille pigeons. Et si je vous eusse aussi bien cogneu au commencement de ma dispute, comme je fay à ceste heure, je vous jure en vérité que ne me fusse pas prins à vous en faict de dispute.
\end{abstract}

En otra intervención, Frère Anselm recuerda un hecho ocurrido en Mallorca durante su juventud y que concluyó con la condena a prisión de un clérigo que había participado en la muerte de otro, suceso que el asno cuenta como ejemplo del pecado de la ira. El autor, por lo tanto, accede por medio del asno a dar alguna pincelada de

\footnotetext{
48 Turmeda, ed. cit, 1984, p. 108. Traducción del texto: Señor asno, según el proverbio, «mala capa cubre buen bevedor». Así me pareceis vós. Quien os ve tan negro, roto y sin cola, piensa que no puede encontrar en vós sutileza, sinóo más bien que seaáis ignorante y grosero, si bien ahora pienso que sois un gran astuto y si os hubiese conocido al principio de la disputa, en verdad no me habría embarcado en esta empresa.
} 
su vida en este juego de perspectivas que es la Disputa donde nunca sabremos si la real intención de Turmeda era la burla o la evocación a su pasado cristiano.

\section{COMO CONCLUSIÓN, ¿QUÉ PIENSAN los ANIMALES DE LOS HOMBRES?}

La dignidad humana, que es el tema planteado en la Disputa de Turmeda, tiene un contrapunto en las fábulas de Francesc Eiximenis. El argumento de una de esta fábulas plantea una cuestión entre los animales: decidir quién es el más cortés y noble animal en el mundo. El primero en argumentar es el león que defiende al hombre. Sin embargo, inmediatamente el resto de animales argumentan en su contra, hasta que aparece una cigüeña que le hace ver al león que no siempre las verdades son tan absolutas y genera una discusión sobre los consejeros reales. No obstante, nos interesa destacar los parlamentos del caballo y del asno para saber la opinión que estos animales tienen de los hombres, altamente negativa, por supuesto. En palabras del caballo:

Nós, senyor, servim e honram l'hom fort altament, portant-lo per ciutats e per viles pomposament e fort ricosa; e en les batalles nós nos posam per ell a mort, e el ne traem ab honor, e el portam carregat de ferre, e som-hi nafrats e colpejats e esguerrats, e eixim del camp eromanem morts aquí mateix; e ell, père bones gràcies, quan començam a envellir eperdre lo poder, tol-nos nostre bell arnés, e posen-nos un vil cabestre d'ase al cap e un bast o una albarda de mul a les costes; nos tolen la civada e si no podem anar bé carregats, farten-nos de bastonades; e fan nos jaure a la serena. E quan morim, no els basta lo servei, ans nos giten en casa hòrreament, e ens fan escorxar, e serveixen-se de nostra pell a calçar, e donen nostres carns al scans, ne ens volen soterrar.

A continuación, las quejas del asno son más duras:

Io mesquí, podets dir, senyor, que hi són mala vengut en casa de l'hom, car ell me té per la pus vil bèstia que al món sia, e tots dies me malaeix; e jamés no em carrega sinó fems e vils coses; e jamés no m'honra de fre ne de sella, e contínuament me bat e em trenca; e em dóna a menjar vilment, e fa'm tot menjar a cans!.$^{49}$

En otra fábula eiximeniana, un joven león le dice a su padre que desea ejercitar su fuerza contra los hombres, a lo que el león experimentado contesta que no saldría

\footnotetext{
49 F. Eiximenis, Contes i faules, Barcelona, Barcino, 1925, pp. 125-127. Nosotros servimos y honramos a los hombres, los llevamos por ciudades y villas, en las batallas nos exponemos a la muerte, les propocionamos honor, los montamos cargando con su arnés, somos heridos y abandonados en el campo de batalla. Cuando envejecemos, los hombres nos quitan nuestros arneses y nos ponen un cabestro de asno y unas albardas de mula en los lomos, nos quitan la cebada, nos cargan de trabajo y nos dan bastonazos, nos acompañan de asnos y nos dejan dormir en la serena. Cuando morimos no reconocen nuestros servicios, sinóo que nos expulsan de casa, nos quitan la piel y hacen con ella calzado, dan nuestra carne a los perros y no nos entierran. Yo, mezquino, no soy bienvenido en la casa del hombre; él me tiene por la más vil bestia del mundo, todos los días me maldice, solo me carga con basura y cosas viles, jamás me honra con un freno y una silla, continuamente me golpea, no me da de comer y después de muerto da de comer a los perros mi carne.
} 
bien parado ya que los hombres, y en especial los labriegos, son «los más industriosos y maliciosos y contra ellos jamás se puede salir con honor». ${ }^{50}$

Observamos, pues, que el debate entre hombres y animales es un tema común en las fábulas y otros ejemplos animales en los cuales se plantea la cuestión de la naturaleza bondadosa del hombre y, por extensión, de todas las criaturas, aunque la ignorancia y el deseo de poder provocan la corrupción. En este sentido los animales, ajenos a la sociedad humana, mantienen esta naturaleza bondadosa y pueden dar una lección a la sociedad ideal que pretende establecer Eiximenis en sus obras.

Las figuras del animal y del hombre dialogando aportan una novedad importante en tono satírico. El caballo de la Disputació d'en Buch no nos recuerda al animal noble sino más bien al rocín flaco y desagradable que se dirige al hombre de una forma en principio formalmente respetuosa pero recordándole su vileza. En esta obra, el caballo ríe abiertamente ante las razones que le da su amo para justificar su conducta, se sorprende de que el ladrón no se preocupe por sus actos y, cuando asume el papel de confesor da una serie de consejos propios de un individuo honrado que son desoídos completamente por el caballero En Buch. En el caso de la Disputa del Asno de Turmeda, las intervenciones burlescas del animal son más explícitas y llegan casi a ser insultantes.

Los animales de nuestros relatos parecen tener más juicio que el hombre. En Buch es un ladrón por lo que se presume que no tiene juicio, pero Frère Anselm es un hombre estudioso que no demuestra su valía cegado por el orgullo y cuya vanidad es constantemente vilipendiada por el asno.

La habilidad dialéctica es mayor en los animales, en el caso de Frère Anselm sus intervenciones son muy pobres mientras que el razonamiento del asno es mucho más desarrollado lo que lleva a una refutación contundente. En el caso de En Buch, que también posee recursos hábiles para escapar de la penitencia, el caballo se muestra mucho más convincente.

Como reflexión final, la posible lección moral que se desprende es el razonamiento de que si los animales, sin tener intelecto, pueden llegar a este grado de sutileza. Cuánto mejor sería para los hombres tenerlo en cuenta y aprender de estos seres considerados inferiores.

$\overline{50}$ F. Eiximenis, op cit., 1925, p. 108. 


\section{Bibliografia}

Alemany, R., «Presències i ecos d'un jo individuat en l'obra d'Anselm Turmeda», Estudis de Llengua i Literatura Catalanes, 29 (=Miscel lània Germà Colón, 2), 1994, pp. 5-24.

, «El context literari i intel lectual de la Corona d'Aragó en l'època de sant Vicent Ferrer», en Paradigmes de la història, I: Actes del Congrés Sant Vicent Ferrer i el seu temps (València, 1996), València, Saó, 1997, pp. 47-70.

, «Tradició i innovació literaria en la Disputa de l'Ase d'Anselm Turmeda», en Professor Joaquim Molas; memòria, escriptura, història, 2 vols., Barcelona, Publicacions de la Universitat de Barcelona, 2003, I, 2003. pp. 15-26.

, «Rex est hoc tempore nummus: un motiu goliardesc reciclat per l'Arcipreste de Hita i per Anselm Turmeda», en R. Alemany / F. Chico (eds.) Literatures ibèriques medievals comparades = Literaturas ibéricas medievales comparadas, Alacant, Universitat d'Alacant, Sociedad Española de Literatura General y Comparada, 2012, pp. 39-51.

, «Insectes perspicaces dans une parodie des débats scolastiques», Reinardus.

Yearbook of the International Reynard Society, 25 (2013), pp. 1-10.

ANNICHIARICCO, A., Narracions en vers catalane medievali. Apunti e Materiali per una Guida bibliográfica, Roma, Edizioni di Storia e Letteratura, 2003.

Asín Palacions, M.: «El original árabe de la Disputa del Asno contra fray Anselmo Turmeda», Revista de Filología Española, I (1914), pp. 1-51.

AvenozA, G., «Traducciones Valerio Máximo en la Edad Media Hispánica», en Reflexiones sobre la traducción. Actas del Primer Encuentro Interdisciplinar «Teoría y práctica de la traducción» (Cádiz, 29 marzo- 1 abril de 1993), ed. L. Charlo Brea, Cádiz, Servicio de Publicaciones de la Universidad de Cádiz, 1994, pp. 167180.

BADIA, L., De Bernat Metge a Joan Roís de Corella. Estudis sobre la cultura literària de la tardor medieval catalana, Barcelona, Quaderns Crema, 1988.

, «De la Faula al Tirant passant pel Llibre de Fortuna e Prudència», en Traducció $i$ modernitat als segles XIV $i$ XV. Estudis de cultura literaria i lectures d'Ausiàs March, Barcelona, Valencia, Institut Interuniversitari de Filologia Valenciana/ Publicacions de l'Abadia de Montserrat, 1993, pp. 93-128.

Bestiaris, edición de Saverio Panunzio, Barcelona, Barcino, 1963.

Betlloch, M. I., E. Chiner, J. Chiner, F. Llorca, L. Martín, «The use of animals in medicine of Latin tradition: study of the Tresor de Beutat, a medieval treatise devoted to female cosmetics», The Journal of Ethnobiology and Traditional Medicine, 121 (2014), pp. 752-760. 
Blandin de Cornualla i altres narracions en vers dels segles XIV i XV, edición de A. Pacheco, Barcelona, Edicions 62 / La Caixa, 1983.

CABré, M. Cerverí de Girona and his poetic traditions, London, Tamesis, 1999, pp. 152-179. Cingolani, S. M., El somni d'una cultura: Lo Somni de Bernat Metge, Barcelona, Quaderns Crema, 2002.

EIXIMENIs, F. Contes i faules, Barcelona, Barcino, 1925 , Terç del Crestià, edición de M. Olivar, 3 vols. Barcelona, Barcino, 1929-30.

Epalza, M. de, Fray Anselmo Turmeda (Abdallah al-Taryuman) y su polémica islamocristiana. Edición, traducción y estudio de la «Tuhfa», Madrid, Hiperión 1994. [1 ${ }^{a}$ ed. 1971.]

FARAUDO, L., Recull de textos catalans antics, Barcelona, 1911.

Garcia, M., L. Martín, «Algunes fonts occidentals de l'obra d'Anselm Turmeda Disputa de l'ase», Revista de Filología Románica, 13 (1996), pp. 181-214.

Hauf, A. G., D'Eiximenis a sor Isabel de Villena. Aportació a l'estudi de la nostra cultura medieval, València-Barcelona, Institut Interuniversitari deFilologia Valenciana/ Publicacions de l'Abadia de Montserrat, 1990.

Hillgarth, J. N., «La personalitat política i cultural de Pere III a través de la seua crònica», Llengua \& Literatura, 5 (1993), pp. 7-102.

LACARRA, M. J. «Los enigmas de las Faules d'Isop», Caplletra. Revista Internacional de Filología (en prensa).

LatinI, B. Llibre del Tresor, versión catalana de Guillem de Copons, vol II, edición de C. J. Wittlin, Barcelona, Barcino, 1976.

Llull, R. Llibre de l'Orde de Cavalleria, edición de Albert Soler, Barcelona, Barcino, 1988. , Obres Selectes, edición de Antoni Bonner, Palma de Mallorca, Moll, 1989. [1a edición en inglés, Selected Works, Princeton 1985.]

March, P. Obra completa, edición de Lluís Cabré, Barcelona, Barcino, 1993.

MARCO, M., «La comicitat, la paròdia i aspectes anticlericals en alguns contes plaents catalans: La disputació d'en Buc ab son cavall i el Testament de Serradell de Vic», SCRIPTA, Revista internacional de literatura i cultura medieval i moderna, núm. 2 (2013), pp. 1- 12.

Martín, L., «La Disputa de l'ase d' Anselm Turmeda i la tradició enciclopèdica medieval», dins Juan Paredes (ed.), Medioevo y literatura. Actas del V Congreso de la Asociación Hispánica de Literatura Medieval (Granada, 1993), III, Granada, Universidad de Granada, 1995, pp. 213-227.

, La tradició animalística en la literatura catalana medieval, Alacant, Institut de Cultura Juan Gil-Albert, Universitat d'Alacant, Conselleria de Cultura, Educació i Ciència, 1996.

, «Contribució a l'estudi de la versió catalana de les faules d'Isop i la seua difusió en la literatura medieval», en J.M. Lucía (ed.), Actas del VI Congreso de 
la Asociación Hispánica de Literatura Medieval (Alcalá de Henares, septiembre 1995), vol. 2, Universidad de Alcalá de Henares, 1997, pp. 1123-1137.

«Algunes notes sobre la recepció del Calila e Dimna al català i la Doctrina d'en Pacs», Randa. Homenatge Jordi Carbonell, 60 (2007), pp. 25-39.

, «Nuevas aportaciones sobre la transmisión del Bestiario catalán», Revista de Literatura Medieval, 24 (2012), pp. 155-172.

Massip, J. F. Història del teatre català. Dels origens a 1800, Barcelona, Arola, 2007.

Miquel y Planas, R., Llibre del sabi y clarissim fabulador Isop: historiat y notat als marges del llibre y ara novament corretgit per R. Miquel y Planas en vista de les edicions de 1550 y 1576 y de les posteriorment publicades en català, Barcelona, en casa de Fidel Giró, 1908.

Ottainno, A., «Els fabliaux catalans: anàlisi d'una definició», Miscel lània Joan Fuster. Estudis de Llengua i Literatura, VII; Barcelona-València, Publicacions de l'Abadia de Montserrat, 1993 pp. 5-43.

Pou i Martí J., Visionarios, beguinos y fraticelos catalanes (siglos XIII-XIV), estudio preliminar d'Albert Hauf i Valls, Alacant, Instituto de Cultura Juan Gil-Albert, 1996. [1 $1^{\mathrm{a}}$ ed. 1930].

REDONDO, J., «Les posibles fonts gregues de la Disputa de l'ase de Fra Anselm Turmeda», en C. Bosch \& P.J. Quetglas (eds.), Mallorca i els clàssics, II Ciutat de Mallorca, 2000, pp. 33-48.

Rico, F., El pequeño mundo del hombre. Varia fortuna de una idea en las letras españolas, Madrid Castalia, 1970. "Antoni Canals i Petrarca. Para la fecha y las fuentes de Scipió i Anibal», en Miscel lània Sanchis Guarner, III, Barcelona, Publicacions de l'Abadia de Montserrat, 1992, pp. 53-63.

Romeu i Figueras, J., «Els dos textos catalans del Sermó del Bisbetó», en R. Alemany et al. (eds.) Actes del Novè Col loqui Internacional de Llengua i Literatura Catalanes I, Barcelona, Publicacions de l'Abadia de Montserrat, 1993, pp. 189-231.

Rubió i Lluch, A., Documents per a l'història de la cultura catalana mig-eval, 2 vols., Barcelona, IEC, 1908 [reproducción facsímil con estudio de Albert Balcells, Barcelona, Institut d'Estudis Catalans, 2000].

Tornero Poveda, E., La disputa de los animales contra el hombre (traducción del original árabe de la Disputa del asno contra fray Anselmo Turmeda), Madrid, Universidad Complutense, 1984.

Torroella, G., La Faula, edición de Anna Maria Compagna, Barcelona, Publicacions de l'Abadia de Montserrat, 2007.

TurmedA, A., Dispute de l'ane, ed. Armand Llinarès, Paris, Vrin, 1984. 